\title{
Perceptions and expectations of corporate social responsibility: Theoretical issues and empirical findings
}

\author{
D.A.L. Coldwell \\ School of Economics and Management, University of Natal, Republic of South Africa \\ Email: coldwell@nu.ac.za
}

Received October 2000

\begin{abstract}
This paper focuses on the issue of differences in individual perceptions and expectations of corporate social performance (CSP). Business research has indicated, somewhat equivocally, that there is evidence to support possible causal relationships between CSP, corporate reputation (CR) and financial performance (CFP). The paper analyses these relationships with regard to various causal explanatory models delineated by Carroll and Buchholtz (2000). Specifically, the paper considers the theoretical possibility of CR being a moderating variable in the relationship between CSP and CFP.
\end{abstract}

The paper reports the findings of an empirical study of University students' perceptions regarding CSP in South Africa, which show that significant differences between black and white student expectations of CSP exist. The findings are discussed with regard to building a tentative theoretical model of CR.

\section{Introduction}

\section{The corporate social performance/financial performance relationship}

Before going on to discuss the relationship between corporate social responsibility and financial performance, it is necessary to define the specific concepts being used. Corporate social responsibility is defined by Robbins (1994:123) as: '.... a business firm's obligation, beyond that required by the law and economics, to pursue long-term goals that are good for society'. Boone and Kurtz (1999:54) state that: 'Social responsibility is management's acceptance of the obligation to consider profit, consumer satisfaction, and societal wellbeing of equal value in evaluating the firm's performance'. The concept of corporate social responsibility needs to be distinguished from corporate social responsiveness and corporate social performance although all three concepts are closely related. According to Ackerman and Bauer (1976), corporate social responsiveness denotes an action orientation towards a corporation's social responsibility or its perceived obligations towards society. Sethi (1975) suggests three distinct stages in his model of corporate social performance. Stage 1 consists of social obligation in so far as the corporation recognizes its economic and legal obligations to society. Stage 2 'social responsibility' is achieved when the corporation conforms to the prevailing norms and expectations of social performance in a given society. Finally stage 3 , the stage of social responsiveness is reached when the corporation goes beyond responding to prevailing social pressure and takes a longer term, anticipatory and preventative approach to its social performance.

Frederick (1994) distinguishes between two basic types of corporate social responsiveness: $\mathrm{CSR}_{1}$ and $\mathrm{CSR}_{2}$ The latter refers to how effectively the corporation responds to social pressure. It is pragmatic and action orientated. The emphasis is on the readiness to respond rather than the content of the actual response.

Perhaps Carroll (1979) offers the most comprehensive model of corporate social performance. Very briefly, Carroll's (1979) three-dimensional model consists of economic, legal, ethical and discretionary social responsibility categories. The model relates social responsiveness that can be reactive, defensive, accommodating or proactive to specific social issues (consumerism, the environment, discrimination, product safety, occupational safety and shareholders). The concept of corporate social performance as used in the current study emphasizes the ethical and discretionary aspects of Carroll's (1979) model and also embraces the notion of a proactive responsiveness to social performance expectations. However, the specific social issues of Carroll's (1979) model are not articulated in the operationalized concept of corporate social performance in this study, as different social issues have different salience to specific individuals. What was considered of greater importance was the individual's overall attitude toward CSP and, more specifically, perceptions of the gap between actual and expected CSP. In short, the operationalization of the concept of CSP in the empirical study reported in this paper emphasizes the notion of the responsibility of businesses operating in South Africa to society and the community, beyond their purely legal and economic ones. The concept of social performance as it is used in the empirical study thus specifically focuses on the extent to which business is perceived as proactively conducting its affaires in an ethical manner and using its resources for social upliftment. 
Corporate social performance can therefore be viewed against a backcloth of individual perceptions regarding businesses' social responsibilities and perceptions of their actual and expected performance with regard to these responsibilities. Corporate reputation (CR) vis-á-vis corporate social responsibility can be defined as the extent to which corporate social performance meets individual expectations of businesses' social responsibilities. Thus, individual perceptions of corporate social responsibility lie behind individual assessments of corporate social performance and corporate reputation. Where a gap is perceived to exist between perceptions and expectations of CSP, this will lead to specific CSP and CR assessments (this aspect is dealt with in detail later in the paper).

Corporate financial performance can be measured in different ways including appreciation of company profits and/or company stock over a specific time period.

Carroll and Buchholtz (2000) present three perspectives regarding the CSP, CFP and CR relationship.

Perspective 1 suggests that good CSP generates good corporate financial performance which in turn generates a good corporate reputation. The good corporate reputation enhances the corporate financial performance, which leads to a further improvement in CSP. This perspective as Carroll \& Buchholtz (2000) point out, has been studied extensively over the last 20 years with inconclusive results.

A recent study by a Chicago based Investment Company suggested that CSR pays. The study indicated that 200 companies ranking highest on their CSR measuring instrument had outperformed the Standard and Poor's 500 stock index between 1988 and 1992. (Carroll \& Burchholtz, 2000:54).

In South Africa, the Infrastructural, Development \& Environmental Assets (Ideas) fund managed by Old Mutual asset managers posted a return of around 25 per cent for 1999 , indicating that investment funds which are socially responsible make money (Business Day, 5/5/2000:27).

Perspective 2 suggests that good corporate financial performance generates good corporate social performance and builds a good CR. Furthermore, a good corporate reputation engenders good CSP that in turn improves CFP. Preston and O'Bannon (1997) found that financial performance either precedes or occurs simultaneously with social performance, thus providing support for this perspective. The social performance/financial performance perspective has strong face validity in that good financial performance provides the funds required for a superior corporate social responsibility performance. All the studies that have looked at this relationship have methodological weaknesses related to measures of 'social responsibility' and 'financial performance'. As Robbins (1994:124) puts it: 'Most (studies) ascertain a firm's social performance by analyzing the content of annual reports, citations of social actions in articles on the company, or public perception 'reputation' indexes... whereas measures of economic performance (net income, return on equity, or per share stock prices) are more objective, they are generally used to indicate only short-term financial performance. It may well be that the impact of social responsibility on a firm's profits - either positive or negative- takes a number of years to work itself through'. Clearly, if corporate social performance is to have an effect on corporate financial performance and corporate reputation, it must be driven from the perspective of consumers themselves. In other words, in order to predict the effects of CSP on CFP more accurately, it seems necessary that the essential driving force in this relationship, which must be individual perceptions of CSP, be, as far as possible, objectively assessed. Another problem with these studies is that while they may be able to show a correlation between CSP and CFP this does not indicate a causal relationship or the direction of causality between the variables.

Perspective 3 maintains that there is an interactive two-way relationship between social performance, financial performance and corporate reputation respectively. In this view the three variables influence each other and it is not possible to identify a primary causal variable.

A fourth perspective can be incorporated, although not specifically discussed by Carroll and Buchholtz (2000), that postulates that good corporate social performance generates a good corporate reputation that leads to enhanced financial performance. Also, that good financial performance leads to further improvements in social performance enhancing corporate reputation and generating further improvements in financial performance. It is this perspective that the paper wishes to discuss and analyze in detail. The plausibility of this fourth perspective is underlined by the fact that it regards corporate reputation as the key explanatory variable in the social performance/financial performance interrelationship. In other words, the key to improved financial performance of a company is not its social performance per se, but the perceptions of particular individuals/customers regarding that social performance. The enhanced reputation that stems from social performance drives individuals to become or remain customers/shareholders of the company. This results in improved financial performance. This perspective introduces the customer's perceptions and expectations regarding corporate social responsibility as the pivotal element in the relationship between the social and financial performances of the firm.

Clearly CFP and CR are influenced by factors other than CSP and the inconsistency in the CSP and CFP relationship can be attributed to the fact that there are a host of possible independent variables that may in any given situation have an effect on CFP in different circumstances. However, where specific individuals and/or groups deem CSP to be important, possibly even the most important aspect of company performance, it seems reasonable to expect that it will influence their investment and buying decisions regarding that company. 


\section{The actual and expected corporate social performance gap}

\section{Carroll and Buchholtz's model}

Carroll and Buchholtz (2000) present a model of the actual and expected performance CSP gap indicated in Figure 1.

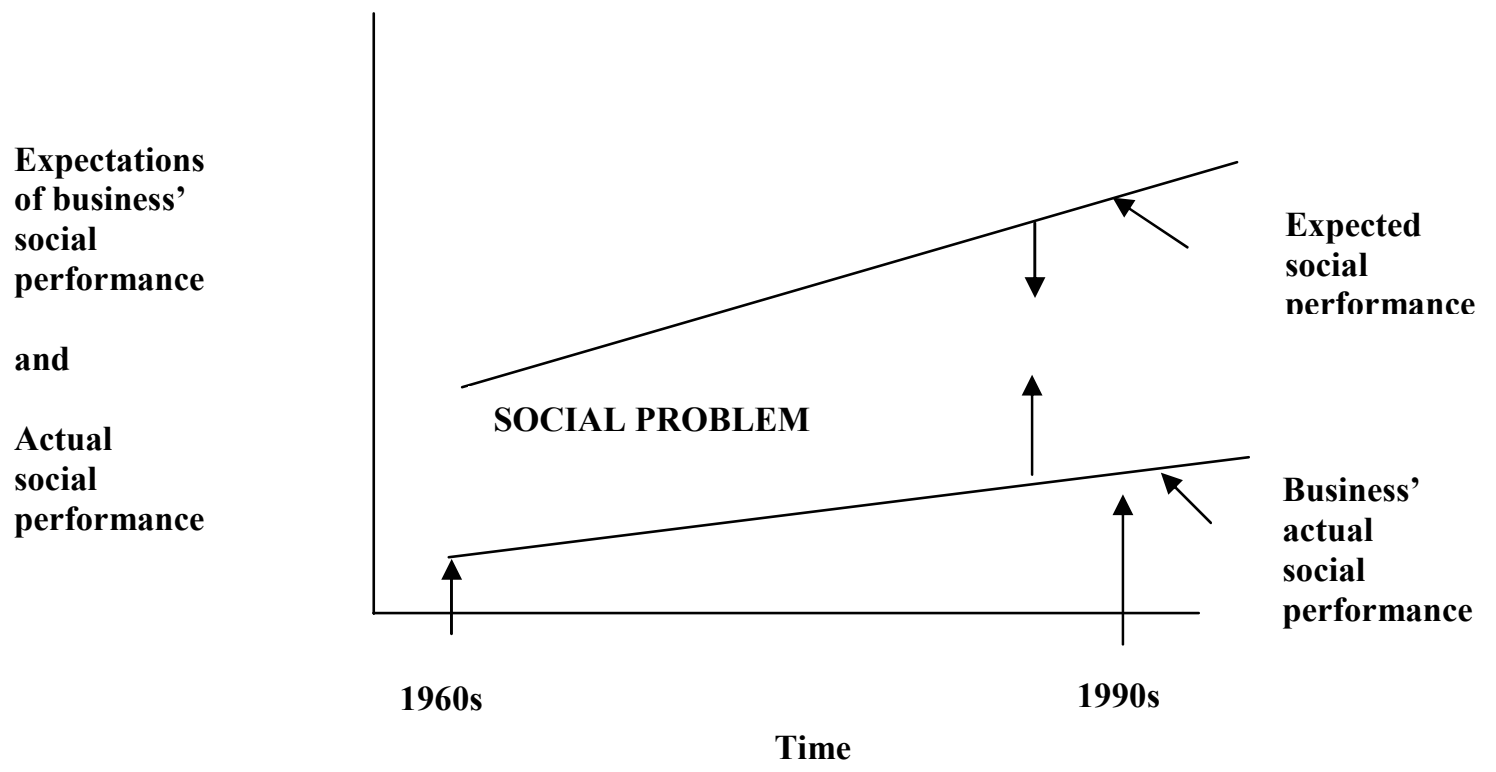

Figure 1: Society's expectations versus business' actual sociaı periormance (adapted from Carroll and Buchholtz, 2000)

Figure 1 illustrates what Carroll and Burchholtz (2000) refer to as a 'revolution of rising expectations'. This can be defined as the belief that each succeeding generation expects to have a standard of living and quality of life that is higher and therefore that its expectations of business CSP is higher, than that of the preceding one. Carroll and Burchholtz (2000) suggest that the gap between actual and expected business social performance has widened in the last 30 years. However, they also maintain that although the upward trend of rising expectations continues, the widening gap has been tempered to some extent by increasing levels of crime, poverty, unemployment, homelessness, environmental pollution and AIDS. The increase in social problems of these kinds has had the effect of dampening the upward trajectory of rising expectations since people are beginning to recognize the fact that a constant rise in living standards may not be realistically possible. The model presented by Carroll and Buchholtz (2000) is plausible but is based on largely historical evidence which they and other authors have analyzed (see for example Cannon, 1994 and Jacoby, 1973). Carroll and Buchholtz (2000) also indicate that at the level of corporate social responsibility, this model refers to the problem created by the gap between society's expectations of businesses' social performance and its actual social performance. However, the nature of the actual/expectation CSP gap is not operationalised for testing empirically in these studies, so it is not possible to assess the internal or external validity of the model, particularly in non-Western situations. Given the legacy of human rights infringements that characterized the apartheid government and the laws under which business operated at that time; it would not be unreasonable to expect a large gap between
South Africans' perceptions of the actual and expected corporate social performance. In fact, as is reported in the empirical section of this paper, this was discovered to be the case.

\section{The findings of the empirical study}

Instruments to measure individual perceptions of actual and expected CSP were devised partly based on a modified version of a scale drawn up by Trevino and Nelson (1995) and used in a representative sample $(\mathrm{n}=133)$ of third year university students studying accountancy. Although representative of accounting students, the sample is small and unrepresentative of the population as a whole. Thus the findings, particularly those regarding the general validity of Carroll and Buchholtz's (2000) model, must be regarded as tentative. The measuring instruments consisted of two distinct sections. One section, initially consisting of 10 items aimed at measuring perceptions of CSP and included items such as: 'Business persons only care about making a profit' and 'The profit motive pressures managers to compromise their ethical concerns.' The second section that also initially consisted of 10 items focussed on individual expectations regarding CSP. This section includes items such as: 'Business must spend more on social upliftment' and 'An ethical business is one where moral business behaviour is conducted in spite of lower profits for the company.' The items of the measuring instruments were arranged on a five point Likert-type scale ranging from 'strongly agree' to 'strongly disagree' and administered in a self-completion questionnaire. Other data itemized in the questionnaire included: age, gender, ethnic group and home language. 
The internal consistencies of the measuring instruments for perceptions and expectations on CSP were found to be 0.78 and 0.71 (Cronbach alpha) respectively after both instruments had been reduced to 6 items. In short the reliability of the instruments was regarded as being acceptable. The construct validity of the instruments was assessed using factor analysis. Very briefly, a Kaiser MeyerOlkin measure of sampling adequacy of 0.678 was obtained which was considered 'middling' (Kaiser \& Rice, 1974) factor analytical material. A non-orthogonal rotation method was adopted as it was felt that this approach would test the conceptual discreteness of instruments thoroughly. Three interpretable factors emerged from the analysis. Two of the factors appeared to measure different dimensions of perceptions of CSP (interpreted as perceptions of managerial practice and general business approach to CSP). Although they explained different aspects, they appeared to embrace the same underlying dimension that was interpreted as 'perceptions of CSP'. A third factor which was interpreted as 'expectations of CSP', clearly emerged from the analysis. The three factors explained 51.4 percent of the variance. The factor analysis therefore seemed to confirm the validity of the 'expectations of CSP' concept and offer tentative support for the 'perceptions of CSP' concept.

A high-low mean difference chart of mean scores for black and white students on the perception and expectation of CSP measuring instruments was used to test Carroll and Buchholtz's (2000) model. The findings are indicated in Figure 2.

Figure 2 indicates using a high-low mean difference chart that on average, white student perceptions of CSP (P) scores exceed their expectations of CSP scores $(\mathrm{E})$, mean $\mathrm{P}=25>$ mean $\mathrm{E}=20.3$.
On the other hand, black student expectations of CSP scores exceed their perceptions of CSP scores; mean $\mathrm{E}=24.6>$ mean $\mathrm{P}=21.5$. The differences between these scores for black and white students were tested using paired sample $\mathrm{t}$ tests. Paired sample $\mathrm{t}$ tests for black students' mean scores on $\mathrm{E}$ and $\mathrm{P}$ indicated a significant difference $(\mathrm{t}=2.705, \mathrm{p}=0.01)$. Similarly, paired sample t tests for white students showed a significant difference between $\mathrm{E}$ and $\mathrm{P}$ mean scores $(\mathrm{t}=$ 2.994, $\mathrm{p}=0.006)$.

These findings suggest tentatively that in a relatively small sample of South African students it is not possible to talk of a gap consisting of an expectations of CSP curve that is consistently above a perceptions of CSP curve in the manner suggested in Carroll and Buchholtz's (2000) model.

The evidence clearly suggests that the perceptions/expectations of CSP gap is not one consisting purely of two parallel lines but where intersections are possible.

From a theoretical point of view this suggests that the problem created by the gap between perceptions and expectations of CSP is sometimes qualitatively different from that identified by Carroll and Buchholtz (2000).

This finding is important not only because it adds a different dimension to the existing model, but also because it sheds light on the importance of corporate reputation as a factor in the $\mathrm{CSP} / \mathrm{CFP}$ relationship. It also offers a reason for inconsistencies in the empirical research findings obtained to date analyzing this relationship.

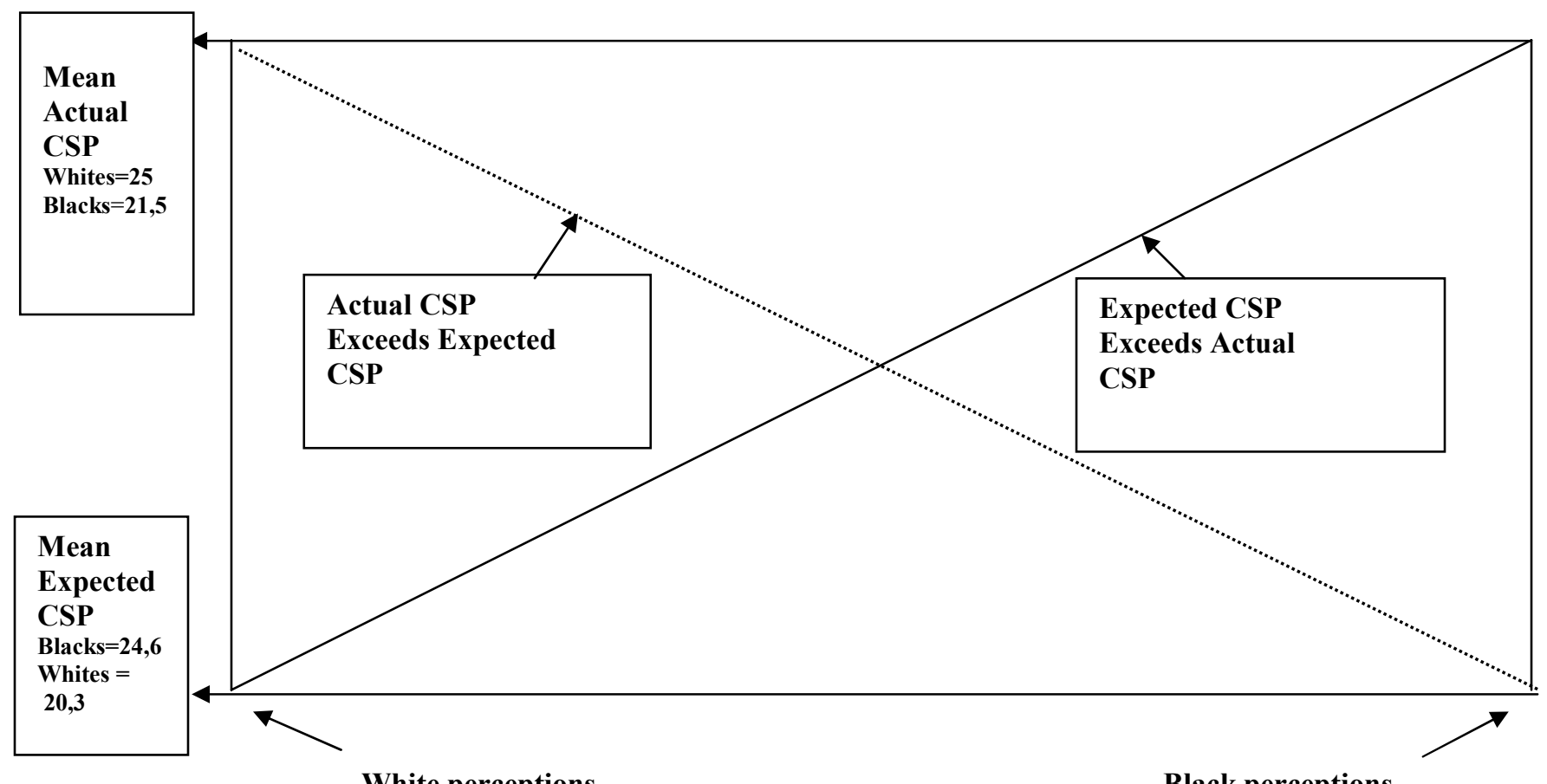

Figure 2: High-low mean scores 
The effects of expected and actual perceptions of CSP on CR: Some theoretical issues

Table 1 describes the various expectations/perceptions of CSP possibilities and identifies their likely effects on corporate reputation.

Table 1: The effects of expected and actual CSP on CR

\begin{tabular}{|c|l|c|c|c|}
\cline { 2 - 5 } \multicolumn{1}{c|}{} & \multicolumn{1}{|c|}{$\begin{array}{l}\text { Individual } \\
\text { perception }\end{array}$} & \multicolumn{3}{c|}{ Effect on CR } \\
\cline { 2 - 5 } C & $\begin{array}{l}\text { Expectations } \\
\text { exceed } \\
\text { actual } \\
\text { Cocial } \\
\text { socitive } \\
\text { performance }\end{array}$ & Negative & Neutral \\
\hline & $\begin{array}{l}\text { Actual } \\
\text { social } \\
\text { performance } \\
\text { exceeds } \\
\text { expectations }\end{array}$ & $\checkmark$ & $\checkmark$ & $\checkmark$ \\
\hline & $\begin{array}{l}\text { Actual } \\
\text { and } \\
\text { expected } \\
\text { social } \\
\text { performance } \\
\text { are } \\
\text { equal }\end{array}$ & $\mathbf{X}$ & $\mathbf{X}$ & $\checkmark$ \\
\hline
\end{tabular}

Table 1 indicates the various possibilities arising from a gap in perceptions of actual and expected CSP and the effects on CR.

Where individual expectations exceed perceptions of actual CSP there are three possible outcomes regarding CR. This perceptual gap can generate either positive or neutral or negative CR outcomes. Where corporate social performance is an important individual decision-making criterion, the reputation of a company that is perceived to under-perform in terms of personal expectations is likely to be negative. For those individuals who are unconcerned about the social performance of the organization, the effect on CR is likely to be neutral (the relative likelihood of these outcomes is indicated by means of a tick in the appropriate boxes in Table1). A positive CR outcome when expectations exceed perceptions of actual CSP is seen as being unlikely (indicated by a cross in Table1). From a behavioural point of view, this suggests that those individuals whose expectations exceed their perceptions of actual CSP, thus undermining the $\mathrm{CR}$ of a company, are less likely to invest in, or purchase goods or services from that company. Thus in so far as this expectation/perception gap is a widespread phenomenon held by a large number of the existing or potential clientele of the company, it can be expected to negatively affect the company's financial performance.

If actual social performance exceeds expectations it is possible, as Table 1 indicates, for there to be either a positive or negative or neutral effect on corporate reputation. A positive CR effect is the likely outcome for those individuals who value CSP and perceive the company to be performing in an exemplary manner in this respect. However, for those who hold a more hard-nosed approach to the business of business, this perception/expectation gap may be regarded as a negative feature of the company concerned and lead to erosion in CR. A neutral reaction is also possible by those who do not value the company's CSP in spite of it being above their individual expectations.

A positive affect on CR is likely to enhance the CFP if through its perceived superior social performance it attracts a larger clientele and/or it motivates its existing clientele to invest in or purchase more from the company concerned.

Finally, if individuals perceive the actual and expected company social performance to be in equilibrium, i.e. there is no evident gap between the two phenomena, the outcome on CR is likely to be neither positive nor negative. As Table 1 indicates, the most likely outcome is neutral. This is because equilibrium between expectations and perceptions of CSP are unlikely to have any effect on CR which will remain more or less unchanged, thus having little or no effect on CFP.

Interestingly, the analytical framework used in Table 1 suggests that a neutral CR outcome is the most likely when positive, negative and neutral CR outcomes are reviewed as a whole. This suggests that in most situations CSP is not likely to have any noticeable effect on CR or CFP. Furthermore, Table 1 suggests that a negative outcome on CR and CFP is more likely than a positive one. This may provide a plausible reason for the equivocal nature of empirical studies' findings regarding the CSP/CFP relationship. And it may also provide a theoretical structure that is supported by circumstantial evidence that suggests that when CSP is perceived to be either poor or too extensive, it is more likely to have a negative effect on CR and sometimes CFP. For example, Nestlé who produce a breast milk substitute for infants has been accused of wrongfully marketing its product in developing countries where access to uncontaminated water is not always possible, and where low levels of literacy make it difficult for mothers to understand and follow the detailed instructions on preparation and hygiene. In short, Nestlé is perceived as not being socially responsible by marketing a product in the developing world that is only necessary for a small minority of infants (Taylor, 1998). There is little doubt that this has negatively affected Nestlés corporate reputation although there was no measurable impact on financial performance (Wyburd, 1998). However, this was not the experience of Redux marketed by American home Laboratories. This product was marketed as a diet pill for the estimated 40 percent of Americans who are overweight. The product was aggressively and irresponsibly marketed as being suitable for all overweight people when in fact it was only really appropriate for the obese, whose risk from death from excessive weight outweighed the risk of death from pulmonary hypertension brought on by the pills themselves. This led to the financial undoing of the Redux product (Kotler, 1998).

Negative CRs can also arise when individuals perceive business as being too socially responsible and neglecting the 
prime purpose of business that is to make a profit (Friedman, 1970). Finally, there are a growing number of people who perceive the socially responsible business ethic as nothing more than a self-interested public relations exercise. 'Now every big company talks about ethics. They talk about the environment. They talk about having fun. They all spend a fortune on social audits. The difference is that these ideals are fiercely self-interested. The British gambling consortium Camelot-which could not be more New Age if it tried - has just published a report showing what a fine ethical company it is. The fact that it is hoping to get its UK lottery license renewed is probably no coincidence' (Kellaway, 2000:21).

In short, a negative reaction to gaps between perceptions and expectations of CSP would seem to be a relatively likely outcome and one that the circumstantial evidence suggests may be more rapid and direct on CR and CFP. In other words, the causal interval between negative gap perceptions may be shorter and easier to demonstrate empirically than positive CSP perceptions and their effects on CR and CFP.

\section{Conclusion}

The investigation has tried to contribute empirically and theoretically to the important debate relating to the nature of the $\mathrm{CSP} / \mathrm{CR} / \mathrm{CFP}$ relationship.

Empirically the investigation has shown tentatively in a small sample of students, that it is possible to question the assumption of an expectations/actual perceptions of CSP gap of the kind suggested in Carroll and Buchholtz's (2000) model. In other words, the study has tentatively suggested that it is not always possible to conceive of expectations as being consistently above perceptions of CSP. Differences between the perceptions of individuals belonging to different ethnic groups have been shown to exist in the South African situation, but the behavioural outcomes establishing the relationship between CR and CFP suggested in Table 1 require extensive further empirical research.

From the theoretical point of view the investigation has, having established that the perceptions/expectations CSP gap is not invariant, put forward an analytical model describing possible CR outcomes. Further empirical research needs to be directed towards

- $\quad$ measuring corporate reputation;

- establishing the relationship between individual perceptions/expectations gaps and the CRs of specific companies and their purchasing and/or investment decisions; and

- analysing their effect on these companies' financial performances.

An important aspect of any future research undertaken would be to increase the sample size used so that the external validity of the findings of the research reported in this paper can be more thoroughly examined

\section{References}

Ackerman, R. \& Bauer, R. 1976. Corporate social responsiveness: The modern dilemma. Reston VA: Reston Publishing Company.

Boatright, J.R. 2000. Ethics and the conduct of business. New Jersey: Prentice-Hall.

Boone, L.E. \& Kurtz, D.L. 1994. Business and society. New York: Harper Collins.

Business Day, 2000. Social responsibility can be profitable, fund shows. May, 5:27.

Cannon, T. 1994. Corporate responsibility: A textbook in business ethics, governance, environment, roles and responsibilities. London: Pitman.

Carroll, A.B. 1979. 'A three dimensional conceptual model of corporate performance', Academy of Management Review, 4:495-505.

Carroll, A.B. \& Buchholtz, A.K. 2000. Business and society: Ethics and stakeholder management. United States: South-Western.

Frederick, W.C. 1994. 'From $\mathrm{CSR}_{1}$ to $\mathrm{CSR}_{2}$ : The maturing of business-and-society thought', Business \& Society Review, 33:150-164.

Friedman, M. 1970. The social responsibility of business is to increase its profits. In Larner, R.A. Ethics in the workplace: Selected readings in business ethics. United States: West Publishing Company.

Jacoby, N.H. 1973. Corporate power and social responsibility. New York: Macmillan.

Kaiser, H.F. \& Rice, J. 1974. 'Little jiffy mark IV', Educational and Psychological Measurement, 34:111117.

Kellaway, L. 2000. 'Hard cash melts façade of New Age firms', Business Day, June 22:21.

Kotler, P. \& Armstrong, G. 1998. Principles of marketing. New Jersey: Prentice-Hall.

Preston, L.E. \& O'Bannon, D.P. 1997. 'The corporate social-financial performance relationship: A typology and analysis', Business and Society, 36:419-429.

Robbins, S. P. 1994. Management. New Jersey: PrenticeHall.

Sethi, S. P. 1975. 'Dimensions of corporate social performance: An analytical framework', California Management Review, Spring: 58-64.

Taylor, A. 1998. 'Violations of the international code of marketing breast milk substitutes: Prevalence in four countries', British Medical Journal, 316:1117-1122. 
Trevino, L. K. \& Nelson, K.A. 1995. Managing business ethics. New York: John Wiley.

Wyburd, G. 1998. Competitive and ethical. Kogan Page: London. 